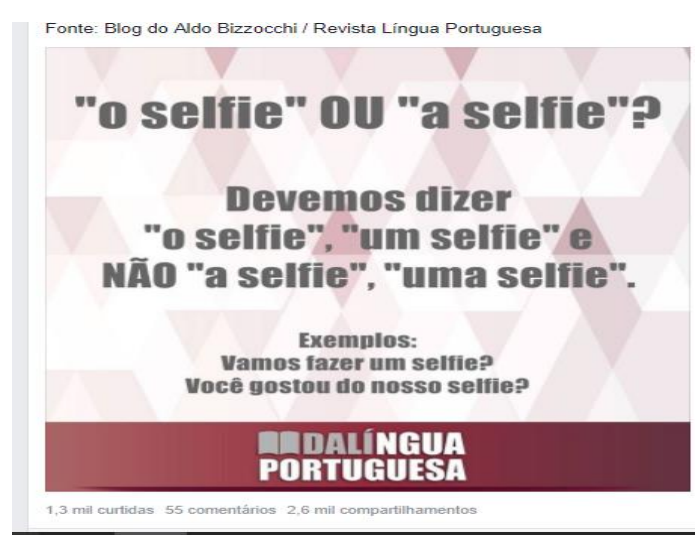

\title{
Da opacidade da palavra selfie no discurso digital
}

The opacity of the word selfie in digital discourse

\author{
Maraline Aparecida Soares 1 \\ ORCID: https://orcid.org/0000-0002-3915-9751 \\ Silvia Regina Nunes 2 \\ ORCID: https://orcid.org/0000-0002-3104-6138
}

Resumo: O estudo que constitui este trabalho de pesquisa, fundamenta-se nos princípios teóricos e analíticos da Análise de Discurso, uma teoria linguística de caráter interpretativo que considera a relação língua, sujeito e história como indissociáveis. Deste modo, a reflexão desenvolvida concentra-se na produção de sentidos sobre a palavra selfie. Analisamos como o discurso digital sustenta a constituição desta palavra. Além disso, problematizamos como se configura uma memória da língua sobre a palavra selfie no espaço de enunciação brasileiro e nos posicionamos criticamente à definição formulada nos dicionários de língua inglesa e portuguesa, apostando nas diferentes historicidades constituídas entre o gesto de se auto fotografar e a relação com a palavra selfie.

Palavras-chave: Língua; Subjetividade; Estrangeirismo; Discurso; Tecnologia; Autorretrato;

Abstract: The study that constitutes this research work is based on the theoretical and analytical principles of Discourse Analysis, a linguistic theory of interpretive character that considers the relationship between language, subject and history as inseparable. Therefore, the reflection developed focuses on the production of meanings about the word selfie. We analyze how the digital discourse supports the constitution of this word. Moreover, we problematize how is configured a language memory about the word selfie in the Brasilian enunciation space and we take a stand on critically to the definition formulated in English and Portuguese dictionaries, betting on the different historicities constituted between the gesture of take picture of yourself and the relationship with the word selfie.

Keywords: Language; Subjectivity; Foreignisms; Discourse; Technology; Self-portrait.

\footnotetext{
1 Doutoranda e Mestre em Linguística pelo Programa de Pós-Graduação em Linguística - PPGL, da Universidade do Estado de Mato Grosso (UNEMAT). Professora contratada no departamento de Letras da Universidade do Estado de Mato Grosso. Pesquisadora do grupo Discurso e Mídias Sociais. Endereço eletrônico: maralinesoares@hotmail.com.

2 Doutora em Linguística pela Unicamp. Docente na Universidade do Estado de Mato Grosso, onde atua na Graduação e no Programa de Pós-Graduação em Linguística. Líder do grupo de pesquisa Discurso e Mídias Sociais. Endereço eletrônico: silvianunes@unemat.br
} 


\section{Introdução}

A tecnologia, em seus diversos aspectos, tem estado na base do desenvolvimento de novas práticas de linguagem e na ressignificação de algumas já existentes. A linguagem dá condições para que a tecnologia seja possível e quando isso ocorre, a tecnologia amplia as formas da linguagem. Nesse jogo, de um movimentar o outro, a tecnologia não se mantém sem a linguagem e suas possibilidades, e recorrendo a ela, explora sua propriedade que permite a existência das formas de significar.

A Selfie é um exemplo dessa relação entre linguagem e tecnologia, sendo uma modalidade de imagem fotográfica, em que, o fotógrafo, tira/faz foto de si, para pôr em circulação a partir da conectividade permitida pela Internet. Nesse sentido, compreendese que selfie tem uma particularidade distinta, seu surgimento não é datado no mesmo período em que o autorretrato passou a existir e os instrumentos de realização de ambos não são os mesmos. Para a Análise de Discurso essa é uma questão importante.

Autorretrato e selfie são formas de significação pelo gesto que produz sentidos para e por sujeitos, cada um de maneira específica, relacionada ao seu lugar de circulação, em tela no museu ou em uma página nas redes sociais, pois consideramos conforme Orlandi (2012) "Que os sentidos são como se constituem, como se formulam e como circulam".

O estudo da significação pelo gesto em ambas modalidades de registro de si (selfie e autorretrato), mostra-se um campo frutífero, mas não é o nosso interesse específico neste trabalho. Inclusive já se encontra em circulação análises que desenvolvemos sobre o gesto, a prática e a imagem fotográfica. Nosso enfoque, neste momento, se volta para o estudo da palavra selfie, considerada um neologismo.

Apresentamos como as condições de produção do discurso digital permitiram a formulação e circulação da palavra selfie com o sentido de imagem fotográfica, uma vez que antes das redes sociais existia apenas self-portrait/autorretrato. Nessa direção, consideramos também que o discurso digital não promove isso sozinho, nenhuma palavra surge sem a inscrição numa memória, sempre haverá relação com o já dito. 


\section{Princípios teóricos e procedimentos analíticos}

Para iniciar a reflexão, fizemos um mapeamento das definições propostas para a palavra selfie. Recorremos ao blog do dicionário Oxford3 que lançou o termo selfie como a palavra do ano, em 2013, e o incluiu como verbete na versão online do dicionário. Também consultamos nos dicionários de Língua Portuguesa do Brasil, em formato digital, para saber se já incluem ou não selfie como verbete, e se o incluem como definem. Porém não encontrando, recorremos aos dicionários online de Língua Portuguesa de Portugal: Infopédia, Priberam e Dicio.

A razão da escolha por dicionários online está para o fato de que, com o avanço da tecnologia e a facilidade no acesso à Internet, os dicionários online são mais acessíveis e, portanto, mais acessados. $\mathrm{O}$ estudo dos dicionários não é algo novo no campo das pesquisas na Análise de Discurso. Há uma vasta pesquisa muito bem elaborada sobre essa temática, e o estudioso José Horta Nunes é uma referência nesse campo. A partir desse estudo fundador sobre dicionários, acrescentamos análises sobre os verbetes de dicionários online, para um melhor entendimento dessa questão.

Em primeiro lugar, significa que o dicionário não é algo que estaria na mente das pessoas desde que elas nascem, mas, sim, algo que é produzido por práticas reais em determinadas conjunturas sociais, ou seja, o dicionário é produzido sob certas condições. E as palavras não são tomadas como algo abstrato, sem relação com os sujeitos e as circunstâncias em que eles se encontram, mas sim como resultantes das relações sociais e históricas, relações essas que são complexas e, por vezes, polêmicas ou contraditórias. Assim, o dicionário é visto como um discurso sobre a língua, mais especificamente sobre as palavras ou sobre um setor da realidade, para um público leitor, em certas condições sociais e históricas. (NUNES, 2010, p. 6-7).

A versão digital do Oxford living dictionaries4 define selfie como um substantivo informal, que também pode ser usado com "y" no final: selfy. Afirma também que essa palavra se refere a uma "fotografia que alguém tira de si mesmo", normalmente com um smartphone ou webcam e "compartilha nas redes sociais". Aqui encontramos um apontamento importante dado pelas definições do dicionário, pois é exatamente a questão do compartilhar/circular que sustenta o foco desta pesquisa, de que para ser selfie tem que ser postada e compartilhada nas redes para que haja o processo da circulação.

3 Disponível em https://blog.oxforddictionaries.com/2013/11/18/word-of-the-year-2013winner/ Acessado em: 10. Out. 2016.

4Disponível em: https://en.oxforddictionaries.com/definition/selfie Acessado em: 02. Jul. 2016 
O blog da equipe do dicionário Oxford, que elege anualmente a palavra do ano, comumente traz algumas informações sobre a palavra escolhida. Desta forma, recortamos formulações do texto publicado na página que dizem especificamente sobre a formação da palavra selfie. No recorte apresentado abaixo é mencionado o espaço em que o nome (selfie) apareceu pela primeira vez, sendo em fóruns online. Traz também a palavra Selfportraits dando a ideia de que selfie seria uma espécie de sinônimo desta. Vejamos estes fragmentos na íntegra:

The term's early origins seem to lie in social media and photosharing sites like Flickr and MySpace. But usage of it didn't become widespread until the second decade of this century and it has only entered really common use in the past year or so. Self-portraits are nothing new - people have been producing them for centuries, with the medium and publication format changing. Oil on canvas gave way to celluloid, which in turn gave way to photographic film and digital media. As the process became snappier (pun intended) so has the name. And now as smartphones have become de rigueur for most, rather than just for techies, the technology has ensured that selfies are both easier to produce and to share, not least by the inclusion of a button which means you don't need a nearby mirror. It seems likely that this will have contributed at least in part to its increased usage. By 2012, selfie was commonly being used in mainstream media sources and this has been rising ever since5. (Grifos nosso).

Recortamos também outro excerto do texto publicado na página do blog, que diz em termos de língua sobre o funcionamento do sufixo - ie na formação da palavra selfie:

Early evidence for the term show a variant spelling with a $-y$ ending, but the - ie form is vastly more common today and has become the accepted spelling of the word. It could be argued that the use of theie suffix helps to turn an essentially narcissistic enterprise into something rather more endearing. It also provides a tie-in with the word's seemingly Australian origins, as Australian English has

5 As origens iniciais do termo parecem residir em mídias sociais e sites de compartilhamento de fotos como Flickr e MySpace. Mas o uso deste não tornou-se generalizado até a segunda década deste século e só entrou em uso em meados do ano passado. Autorretratos não são novos pessoas o produzem há séculos, mudando o formato e as formas de publicação. Óleo sobre tela transformou-se em celuloide, que, por sua vez, transformou-se em filmes fotográficos e mídias digitais. À medida que o processo tornou-se mais rápido (trocadilho), o nome também. E agora, como os smartphones tornaram-se "obrigatórios" para a maioria, em vez de apenas para os técnicos, a tecnologia assegurou que selfies ficaram mais fáceis de produzir e de compartilhar, inclusive pela inclusão de um botão, o que significa que você não precisa de um espelho próximo. Parece provável que isso tenha contribuído, pelo menos em parte, para o aumento do uso. Até 2012, o selfie costumava ser usado nas principais fontes de mídia, e isso vem aumentando desde então. (Grifos nossos) 
something of a penchant for -ie words - barbie for barbecue, firie for firefighter, tinnie for a can of beer, to name just three6. (Grifos nossos).

Observado os exemplos citados, o blog do dicionário Oxford considera que na Austrália a palavra barbie é uma redução da palavra barbecue, significando ambas a mesma coisa, assim como o exemplo das palavras firie e firefighter. A partir dessa recorrência, afirmam que com a palavra selfie ocorreu a mesma coisa. Mas, da perspectiva da qual analisamos, consideramos que há uma diferença nessa relação. Selfie não significa o mesmo que self-portrait.

Além disso, no Google translate, a hipótese apresentada pelo blog não se aplica a todos os casos citados (barbecue - barbie / firefighter - firie / self-portrait - selfie). Vejamos:

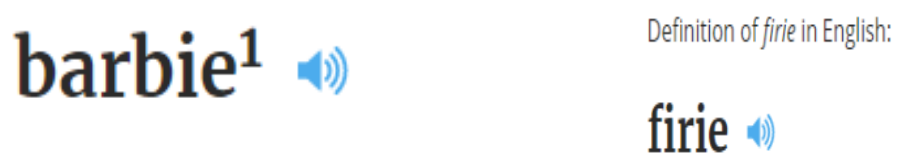

NOUN NOUN

Australian, NZ

informal

A barbecue.

Australian
informal
A firefighter.

'there's always a firie nearby to rescue you or your house from flames'

6 A primeira evidência para o termo mostra uma variante de ortografia com um -y final, mas a forma - ie é vastamente mais comum hoje e tornou-se a ortografia aceita da palavra. Isso pode ser justificado já que o uso do sufixo - ie ajuda a dar um toque essencialmente narcisista em algo bastante mais cativante. Ele também fornece um vínculo com as origens aparentemente australianas da palavra, pois o inglês australiano tem uma propensão para as palavras com o sufixo -ie - barbie para barbecue (churrasco), firie para firefighter (bombeiro), tinnie para uma lata de cerveja, para citar apenas três. 


\section{Definition of selfie in English:}

\section{Definition of self-portrait in English:}

\section{self-portrait}

\section{selfie}

(also selfy)

\section{NOUN}

NOUN

A portrait that an artist produces of themselves.

'a self-portrait of Rembrandt dating back to 1635 '

\section{informa}

A photograph that one has taken of oneself, typically one taken with a smartphone ol webcam and shared via social media.

'occasional selfies are acceptable, but posting a new picture of yourself every day isn't necessary'

Figura 01: Prints da página do Google Tradutor

Ao observar estes exemplos, surgem alguns questionamentos: seria então apenas uma redução do termo self-portrait? Ou a palavra selfie, a partir de um processo de redução tornou-se o nome dado para outra coisa? Quem diz ser uma redução são os discursos prescritivistas (dicionário, gramática, páginas de gramatiqueiros...), mas nos próprios exemplos recortados percebemos que essa definição não se sustenta. Selfie não é sinônimo de self-portrait.

Neste sentido, este trabalho apresenta-se contrário ao que os discursos prescritivistas dizem sobre a formação da palavra selfie - em que defendem ser um diminutivo de self pelo acréscimo do sufixo "ie" e uma "redução" de self-portrait por ser uma palavra que surgiu na Austrália onde se tem o hábito de reduzir uma palavra acrescentando o "ie". Vimos que essa regra não se sustenta, porque selfie não é significada da mesma maneira que self-portrait, como ocorre com os outros exemplos (barbie para barbecue e etc.)

Dessa maneira, o que estamos propondo é uma dessuperficialização da palavra, pensar além da questão de selfie ser apenas uma redução da palavra self-portrait, uma vez que houve a formação de outra palavra que não é autorretrato. Chamamos a atenção para o fato de que ela também pode significar, tanto na língua inglesa, como no português: "Euzinho (a)". O que estamos apresentando são possibilidades de significação que a palavra permite, não é algo estanque como propõem os dicionários.

O que compreendemos analiticamente no discurso dos dicionários é que há uma demanda para que as pessoas entendam que a palavra designa literalmente (espelhando) o sentido de autorretrato, e o que estamos propondo vai contra essa ideia. O que o 
dicionário de língua inglesa, de forma acelerada, quase que na mesma velocidade da Internet, vem fazendo com a palavra selfie é tentar "convencionalizar" um sentido apenas, fechando as outras possibilidades de significação. O que podemos ver nessa escolha da palavra do ano (organizada pela equipe do dicionário Oxford) é uma forma de dar maior visibilidade, de fazer circular na mídia digital sua convenção dada para a palavra, quer dizer, o dicionário sai da "estante" e vai até o sujeito pela rede.

No entanto, ainda há uma diferença entre "entrar" para pesquisar uma palavra no dicionário online, pois esse movimento de busca ainda está muito arraigado a ideia de pesquisa, algo mais academicista, diferentemente do acesso "esporádico" a uma página nas redes sociais. O sujeito é interpelado pelo discurso das redes, de que estando nelas é estar em evidência. Sendo assim, migrar os dicionários para as plataformas digitais é também colocar a língua (homogeneizada) em circulação. Interpelada por esta ideologia, a equipe técnica do dicionário Oxford já tem levado uma versão de sua página para as redes sociais (Facebook, Instagram, Twitter, entre outras). Esse movimento mostra os efeitos da relação da tecnologia digital na língua, ressignificando os modos de constituição, formulação e circulação dos dicionários.

Sobre a palavra selfie, não negamos que haja sim uma relação de semelhança entre elas que está para além da palavra, (selfie/self-portrait), na relação com o gesto marcado pela falta constitutiva do sujeito de linguagem, significado em ambas as práticas, em que o foco é a si mesmo. Mas tomá-las como a mesma coisa é desconsiderar a materialidade própria de cada uma, que será formulada diferente em cada registro, como nos explica Orlandi (2012, p. 11-12): “Os meios não são neutros”. Desse modo, o aparato tecnológico utilizado em cada prática (autorretrato e selfie) implicará também a diferença em cada processo, considerando a constituição, a formulação e a circulação. Pois a tecnologia é resultado do processo histórico e ideológico de cada época.

Reconhecemos que, conforme consta nos textos oficiais de língua inglesa a respeito da palavra selfie, entende-se que sua significação está sustentada numa memória da língua sobre a palavra self-portrait. Para pensar esse processo, recorremos às palavras de Payer:

Com isso estamos ressaltando o quanto, ao se falar sobre a própria língua, enquanto produção humana e sociohistórica, também está se falando de memória, porquanto nela funciona a repetição. A memória trabalha e é trabalhada, pois na própria construção da língua, e isto constitui o fundamento do que entendemos como discurso. Podemos então dizer que há memória na língua. Há memória discursiva já na 
língua, não em uma dimensão suposta como ulterior a ela. Para significar, a língua supõe memória ao se dar como repetição. (2006, p. $39)$.

A partir do que nos diz Payer, temos condições de compreender a respeito dessa palavra, classificada por muitos como neologismo, sendo, no entanto, o resultado de uma relação da memória discursiva com a língua. Sobre essa importante relação, precisamos entender o funcionamento da memória, assim como Payer distingue:

Ao falar sobre este aspecto específico da repetição, gostaríamos de ressalvar, entretanto que não estamos falando da língua "na" memória", no sentido saussureano de um língua "localizada" na memória no sentido de memória de um indivíduo. Falamos, por outro viés, sobre a memória "na" língua, isto é, sobre o modo como os sentidos produzidos e sustentados socialmente, pela repetição, se encontram nisto que chamamos de língua já em seus elementos mínimos. Nesta perspectiva, podemos compreender que o modo como uma sociedade, um povo, produz sentidos historicamente encontra-se marcado em sua linguagem, no modo como ele fala a "sua" língua, ou melhor, a língua que lhe é dado falar por sua história. (2006, p. 39, [Grifos do autor]).

Não tomamos a definição dada pelo dicionário Oxford online como única e fechada, mas consideramos como uma possibilidade de sentido que está sustentada na memória da língua dessa formação social. Entendemos que pode haver uma relação entre a palavra self-portrait com a palavra selfie, há uma marca histórica sustentando esse dizer no contexto da língua inglesa. Entretanto, não podemos incorrer no equívoco de pensar que essa definição seja a única e que o sentido fica fechado apenas ao que foi definido pelo dicionário inglês.

Desse modo, compreendemos que a palavra selfie está sustentada na memória da língua em seu contexto sócio-histórico, sem esquecer que "o digital se apresenta na base da produção discursiva" isso devido à "conjuntura sócio-histórica-ideológica que se constitui com o discurso eletrônico" no espaço de enunciação da língua inglesa. (COSTA, 2016, p. 90).

\section{A palavra Selfie nos dicionários de Língua Portuguesa}

Nos dicionários portugueses de língua portuguesa, recortados para a análise, verificamos que todos apresentam a palavra selfie em sua lista de verbetes. Dentre eles, apenas o Infopédia classifica como "nome feminino", o Priberam afirma ser um "substantivo feminino ou masculino", no Dicio encontramos que selfie é um "substantivo 
masculino e feminino", este dicionário traz ainda alguns sinônimos de selfie: "retrato, fotografia, autorretrato". Todos eles definem o que seria selfie a partir da possível tradução sugerida pelo dicionário Oxford. Apresentam também qual seria o plural de selfie: selfies.

Ao constatar que os dicionários online de língua portuguesa já incluem selfie em seus verbetes não poderíamos deixar de dizer que esse processo é um gesto político. Pois conforme as palavras de Orlandi "o inglês nas condições atuais, já se apresenta como dominante no espaço digital, como língua franca universal da comunicação e do conhecimento, muito em parte pelo apoio tecnológico". (ORLANDI, 2012, apud Costa, 2016, p. 92). Nesse sentido, consideramos que o gesto político nos dicionários portugueses está em se marcar como o atual e completo, porque traz uma palavra de uma língua dita franca e universal.

A circulação de discursos sobre a mediação tecnológica das relações sociais em larga escala e o imaginário produzido acerca da tecnologia e sua capacidade de diminuir distancias, incluir pessoas, dar acesso ao conhecimento e romper limites se justapõem aos interesses que visam ao capital. (COSTA, 2016, p. 92).

Além disso, os dicionários portugueses, com interesses político-econômicos, ajudam a reproduzir o sentido estabilizado. Não é recente que buscam submeter a movência de uma palavra a uma determinada coisa, essa questão vem desde a era clássica. Entretanto, Althusser já alertava sobre essa imaginária transparência, ao afirmar que o caráter da ideologia é produzir evidências, "como todas as evidências, incluindo as que fazem com que uma palavra "designe uma coisa" ou "possua uma significação" (...)." (1970, p. 95). Ou seja, a relação direta palavra-coisa, é instituída ideologicamente, pois a palavra não é a coisa. Por isso há historicidade. É pelo efeito literal que parece que selfie e autorretrato designam as mesmas coisas, contudo as palavras são opacas e equívocas, dependendo das condições de produção.

Desse modo, compreendemos que a palavra selfie está sustentada na memória da língua em seu contexto sócio-histórico, sem esquecer que "o digital se apresenta na base da produção discursiva" isso devido à "conjuntura sócio-histórica-ideológica que se constitui com o discurso eletrônico" no espaço de enunciação da língua inglesa. (COSTA, 2016, p. 90).

\section{A palavra selfie no espaço de enunciação do português brasileiro}


Discursivamente esse fato nos leva a questionar: como essa palavra se significa no espaço de enunciação do Português Brasileiro? Qual a memória de língua (brasileira, portuguesa, americana, australiana) que sustenta seus sentidos? Sendo que, no Brasil, não se tem a mesma historicidade da língua inglesa, e, no entanto, a palavra selfie é usada com enorme frequência no espaço virtual e urbano, estando presente em músicas, comerciais, programas televisivos, estampado em roupas e etc.

Quando se trata do espaço de enunciação7 do Brasil, a primeira questão que devemos apresentar parte do determinante do gênero que se marca na oscilação entre: "o/a"selfie.

A questão que se coloca apresentou-se inicialmente na oscilação de gênero no determinante da palavra selfie no espaço de enunciação da língua portuguesa do Brasil. No período de elaboração de nossa análise, buscamos as pesquisas que vinham sendo desenvolvidas sobre selfie no contexto acadêmico brasileiro. Encontramos alguns artigos de diferentes áreas, inclusive da Análise de Discurso, e em contato com estes textos observamos que todos eles mencionam essa oscilação do gênero, mas por não ser o foco do que pretendiam em seus trabalhos, não problematizam essa questão. Alguns optam por usar uma forma específica e marcada por aspas no decorrer do texto (“o" selfie ou "a" selfie), outros apresentam em todo o trabalho os dois artigos: masculino e feminino, entre parênteses antes da palavra da seguinte maneira: (o / a) selfie.

Diante dessa constatação, consideramos relevante adensar as observações sobre os determinantes que indicam gênero na formulação da palavra, a partir da análise de propagandas relacionadas à prática da selfie para saber se nestes espaços o uso dos determinantes oscilava.

Como resultado dessa observação, apresentamos dois exemplos. O primeiro diz respeito a campanha promocional do Boticários, em que uma cliente pede para "tirar uma selfie" com uma atriz, mas ao realizar o registro verifica a imagem e não se satisfaz com o resultado, pois a atriz não está maquiada. O segundo comercial é da OLX9, sobre os Vikings que estão "desapegando" de alguns utensílios para custear uma viagem para uma

7 Sobre a noção de espaço de enunciação, ver em Semântica do Acontecimento (GUIMARÃES, 2002).

8Link de acesso ao comercial do Boticário: <https://www.youtube.com/watch?v=MIMOMitTcuA > Acessado em: 10. Marc. 2017 9 Link de acesso ao comercial da OLX: 〈https://www.youtube.com/watch? $v=$ DRepzNi82r0> Acessado em 10. Marc. 2017 
segunda lua de mel. No final da propaganda, o casal alcançou o objetivo de realizar a viagem, e estando no local, a esposa chama a atenção do marido para "o selfie". Desse modo, constatamos que nas propagandas e comerciais o gênero do determinativo também oscila, uns utilizam no feminino, outros no masculino.

Também encontramos essa questão circulando nas redes sociais através de posts que tentavam normatizar o uso do gênero para referir-se à palavra selfie, especificamente em páginas do Facebook que compartilham textos fundamentados na perspectiva gramatical "purista da língua", reproduzindo, no espaço das redes sociais, o funcionamento das gramáticas, ditando regras para o uso das palavras.

Analisamos um material publicado na página "DaLíngua Portuguesa”, criada em 2012, por Dali Menezes, graduada em Letras pela Universidade Estadual de Minas Gerais-UEMG, e Pós-graduada em Revisão de Texto na PUC-Minas. A página tem como lema, descrito na foto de capa, o seguinte enunciado:

"Aqui se aprende Português!".

Trazer estas informações sobre a página não é algo aleatório, faz parte das condições de produção, elemento necessário para compreender qual a perspectiva que direciona e sustenta o compartilhamento da postagem que apresentamos a seguir:

\section{facebook cadastese}

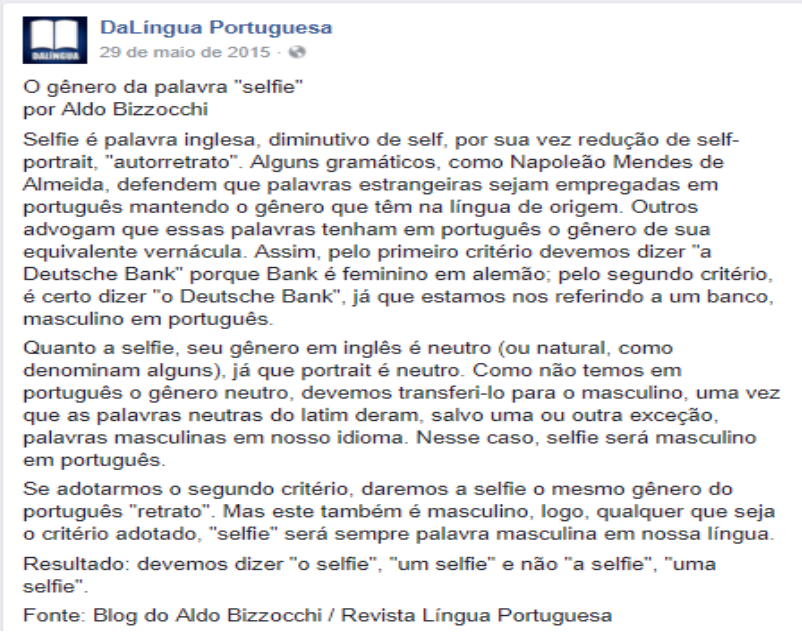

Figura 02: Print da publicação da página DaLíngua Portuguesa

Logo abaixo deste texto escrito, tem-se uma imagem que reitera a produção de sentidos para o texto, em forma de síntese. Vejamos: 


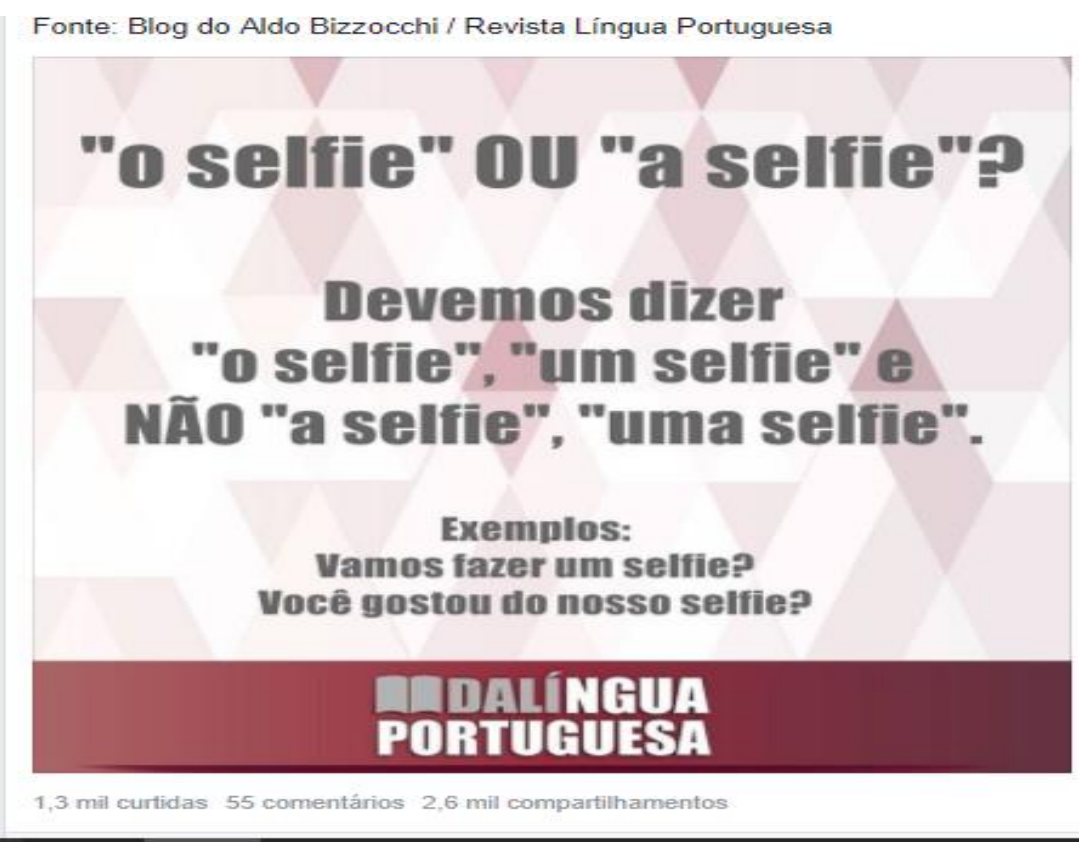

Figura 03: Print da publicação da página DaLíngua Portuguesa

Diante do que se apresenta nos textos publicados, percebemos que a página se inscreve numa posição normativa-prescritiva (deve ser assim e não de outro modo) sobre a língua. Essa concepção se mostra através da disjunção (ou) em que sabendo da existência das duas possibilidades de dizer sobre selfie haverá uma escolha e automaticamente a exclusão da outra. Desse modo, apenas uma poderá ser usada. A significação do "ou" no post está funcionando exatamente como prescreve a gramática: uma conjunção alternativa que "relaciona pensamentos que se excluem." (ROCHA LIMA, 2001, p. 185), como ocorre, por exemplo, no seguinte enunciado: Iremos a pé ou tomaremos um ônibus? O que vemos nas conjunções alternativas é a delimitação de sentidos, não podendo ser dois ou mais.

A posição normativista da palavra, publicada no post, se completa com o verbo “dever" (devemos) no modo imperativo. A gramática institui esse modo para os verbos que se "aplica às ordens que se dão para o futuro e o passado" (ROCHA LIMA, 2001, p.123). O exemplo apresentado na gramática produz os seguintes efeitos: Faça o que eu lhe digo. Faça o que eu lhe disser. Faça o que eu lhe disse.

Sobre esse processo em que a gramática atravessa a língua, Haroche explica:

Os gramáticos procuram, assim, determinar o mais possível o discurso, com um trabalho incessante sobre a precisão do vocabulário e sobre as construções. Determinação do léxico e determinação das construções se inscrevem, neles, em uma concepção geral da língua: esta deve refletir o pensamento com precisão, o que exige uma verdadeira teoria da desambiguização. (HAROCHE, 1992, p. 101). 
Fazer todo esse levantamento que apresentamos nos direciona a pensar o funcionamento da língua que não se deixa controlar. O que pretendemos fazer aqui não é normatizar o uso, delimitando uma forma ou outra como a correta para a utilização do gênero que determinaria a palavra selfie, pois agindo desse modo estaríamos reproduzindo a perspectiva gramatical, algo que foge ao pressuposto da Análise de Discurso em relação a concepção de língua, a qual compreende "a ordem da língua tomada como sistema significante em sua relação com a história, considerada materialidade simbólica, constituída pela ideologia”. (ORLANDI, 1996, apud COSTA, 2016, p. 91).

O que gostaríamos de apresentar, a partir desse material colhido nas observações, é que a língua falha, demostrando assim sua opacidade e equivocidade. O próprio funcionamento da língua não se deixa controlar, pois escapa, assim como vimos na oscilação do gênero. Percebemos que essa questão se dá devido a um apagamento da historicidade e da memória da língua, de uma palavra que é utilizada fora de seu contexto, pois vem do espaço de enunciação da língua inglesa.

No Brasil não podemos dizer que a etimologia da palavra selfie seja autorretrato, pois sabemos que sua origem é inglesa. Porém percebemos que tem um apagamento funcionando, porque até poderíamos, ao invés de dizer selfie, dizer autorretrato, uma vez que "auto" é também um prefixo usado para designar aquilo que é próprio ou que aponta para si mesmo, conforme consta nos dicionários. Assim como a palavra retrato não precisa necessariamente designar pintura, pois até os dicionários que buscam homogeneizar a língua dizem que a palavra retrato pode, também, designar o que se compreende como fotografia. Então a palavra autorretrato também poderia corresponder ao registro feito por uma câmera através de um smartphone pelo próprio fotografado. Porém, a ideologia da globalização institui que a palavra é selfie.

A globalização é um processo geo-histórico de extensão progressiva do capitalismo em escala mundial e que é ao mesmo tempo uma ideologia (neoliberal), uma moeda (o dólar), um instrumento (o capitalismo), um sistema político (a democracia), uma língua (o inglês). (ORLANDI, 2012, p. 07).

Desse modo, o nome usado atualmente no Brasil, e na maior parte dos países (efeito de mundo único quando se trata do digital), para uma fotografia realizada pelo próprio sujeito para as redes sociais é selfie. Percebemos então que os efeitos de sentido 
para a palavra selfie estão relacionados ao gesto. Não temos a mesma historicidade da palavra selfie na língua portuguesa brasileira, assim como no país em que ela foi produzida/falada, especificamente, na Austrália. A historicidade que se forma dessa palavra na língua portuguesa brasileira está atrelada ao gesto/posicionamento de produzir esse tipo de fotografia digital. No que se refere a palavra selfie na língua portuguesa brasileira, a historicidade está relacionada com a própria palavra fotografia. Tal questão é percebida quando encontramos formulações como essa: “Até então, nenhum papa havia batido uma selfie, e o Papa Francisco, como sempre carismático, humilde e de alguma forma moderno (afinal existe até o Twitter do Papa), surpreendeu muita gente".

Na Língua Portuguesa essa questão tem oscilado, não chegando a uma forma única. Ora o gesto de se auto fotografar é designado como um selfie - pensando-se no autorretrato fotográfico (ou nas regras da gramática para uso de estrangeirismos), ora uma selfie - relacionada com a prática (prática e o nome) de fotografia digital. Para nossa discussão, optamos por usar um modo específico, no feminino, uma ou a selfie. Contrariamos a "norma", para exemplificar outra possibilidade de sentido possível, para mostrar como a língua transcende a gramática. Ao fazer uso de uma forma muito recorrente "a selfie", apresentamos como o sentido de um estrangeirismo pode, a partir de uma semelhança entre gestos e não da própria palavra, necessariamente, convocar, pela memória da língua, outra palavra, neste caso a fotografia digital, mesmo que não oficializada. Ou seja, a norma gramatical é implodida pela memória da língua.

\section{Selfie e subjetividade}

Chamamos a atenção para o fato de que ela também pode significar, tanto na língua inglesa, como no português: "Euzinho (a)". O que estamos apresentando são possibilidades de significação que a palavra permite, não é algo estanque como propõem

os dicionários online. É possível trazer a questão da subjetividade no discurso da selfie a partir da própria palavra. Toda a discussão que desenvolvemos sustenta nossa leitura acerca da possibilidade da subjetividade na palavra selfie.

Nesse sentido, compreendemos que a palavra selfie demanda uma relação com a subjetividade sustentada no gesto discursivo de se fotografar, mais do que no sentido da palavra autorretrato. $\mathrm{O}$ próprio espaço das redes sociais dá margem para a manifestação da subjetividade no digital, seu funcionamento é diferente de outros aplicativos, como os de bancos, por exemplo. Percebe-se que o foco principal do Facebook, além dos anúncios 
comerciais, são as informações demandadas sobre o usuário. Exemplo: "No que você está pensando?".

Para pensarmos sobre o modo de constituição da subjetividade na relação com a palavra selfie, utilizamos outros exemplos que são atribuídos ao sujeito e que por isso marcam a subjetividade mesmo sem o sufixo "ie": Self-respect: amor-próprio / selfsufficient: autossuficiente / self-interest: interesse próprio / self-defense: autodefesa, legítima defesa / self-control: autocontrole / self-conscious: inibido, sem naturalidade e myself: eu mesmo. Estes são apenas alguns exemplos extraídos do dicionário Oxford, que apresentam a utilização da palavra self na condição de prefixo. Além destes, tem-se o selfportrait: autorretrato, que se refere tanto ao objeto quanto ao sujeito. Self (Auto) marca o sujeito, enquanto portrait (retrato) marca a produção de uma imagem a partir do sujeito.

O dicionário Oxford na versão online afirma que Self em inglês é designado em três categorias: substantivo, adjetivo e verbo. Dentro dessas classificações define a palavra self, quando na função de substantivo, da seguinte maneira: “A person's essential being that distinguishes them from others, especially considered as the object of introspection or reflexive action 10 ”. Na versão impressa, especificamente na modalidade inglês-português, self é designado pelas palavras "eu", "ego", seguido de um exemplo inicialmente em inglês "She's her old self again”. Que na língua portuguesa quer dizer: "Ela voltou a ser a mesma de sempre". Percebe-se neste exemplo, que quando a palavra self sem os acréscimos de prefixos e sufixos aparece no contexto de um enunciado aponta para uma subjetividade.

A questão é que, mesmo no espaço de enunciação de língua inglesa, em que se alega que a palavra selfie se configura como a redução do termo self-portrait (numa concepção de palavra enquanto coisa), não se pode negar que a expressão é um diminutivo da palavra self, que está na função de substantivo recebendo o sufixo "ie", seguindo a regra utilizada para levar uma palavra para o diminutivo na língua inglesa. Porém, essa não é a única forma. Comumente se utilizam adjetivos como little, small, e tiny. Mas existem casos em que são os sufixos (y),(ie), (ette) e (et) que conferem o grau diminutivo (Dad-papai / Daddy-papaizinho; Dear-querido(a) / Dearie - queridinho(a). Essa questão escapa quando pensamos na palavra selfie. Não há uma relação de diminutivo da palavra

10 "O ser essencial de uma pessoa que o distingue dos outros, especialmente considerado como objeto de introspecção ou ação reflexiva". (tradução nossa) 
alocada a ela a ideia de expressar carinho, como nos exemplos. No caso da palavra selfie essa questão pode estar relacionada a subjetividade.

O que pretendemos aqui não se concentra simplesmente em entender as regras em si, de modo isolado, mas é justamente mostrar como podemos pensá-las discursivamente, para além da relação palavra-coisa. O interessante é como o que se convencionou chamar de sufixo ou, então, de diminutivo, diz do funcionamento da subjetividade. $\mathrm{O}$ discurso lexicográfico não é neutro ao designar o significado para a palavra self acoplada com o sufixo ie, ao invés de continuar utilizando apenas o termo self-portrait. A palavra selfie produz uma série de efeitos de sentidos que vão além de qualquer regra gramatical. Ou seja, o que está na constituição e na formulação desta palavra é da ordem do discursivo, e sendo do discursivo, segue princípios que sustentam uma outra concepção, diferente da lexicografia, de língua e de sujeito. Para pensarmos essa relação do dizer e a subjetividade, recorremos aos estudos de Magalhães e Mariani:

As marcas de subjetividade inscritas no dizer assinalam, simultaneamente, mas sem estarem misturadas ou confundidas, traços do registro inconsciente, da identificação (ou não) a uma determinada formação discursiva e, também, traços do assujeitamento ideológico. (2010, p. 404).

Ao considerarmos as condições de produção que envolvem a constituição da palavra selfie, como o país onde a palavra surgiu que é a Austrália, espaço em que foi formulada pela primeira vez, identificada em um fórum virtual (lugar semelhante as redes sociais digitais), vemos que a criação da "nova" palavra traz as marcas do funcionamento da subjetividade, assim como vimos na citação acima. Desse modo:

Para a Análise do Discurso, o sujeito é constituído pelo esquecimento daquilo que o determina, ou seja, não se dá conta de sua constituição por um processo do significante no funcionamento da linguagem na interpelação ideológica e na identificação imaginária a determinados sentidos. Desse ponto de vista, falar do sujeito é falar de efeito de linguagem; sujeito enquanto um ser de linguagem que foi falado antes de falar, que traz marcas do discurso do Outro, o que implica considerar que o sujeito não é origem do dizer nem controla tudo o que diz. (MAGALHAES e MARIANI, 2010, p. 402-403).

Diante disso, a subjetividade sempre estará relacionada a toda e qualquer manifestação da linguagem praticada pelo sujeito. Por manifestações da linguagem compreendemos como tudo que produz sentidos sendo passível de interpretação. 


\section{Considerações finais}

Ao terminar as observações, descrições e análises desenvolvidas sobre a palavra selfie queremos chamar a atenção para a importância de se compreender a língua para além da estrutura gramatical, perceber que normalmente a estrutura é resultante de um funcionamento discursivo da língua. Entender que as palavras não foram criadas apenas para nomear, mas que elas são também lugar de poder, de dominação, são afetadas por ideologias dominantes. As palavras dizem muito mais do que parecem. Por isso é necessário um trabalho de dessuperficializacão.

Nesse sentido é que constatamos que seria relevante desenvolver um estudo linguístico sobre a palavra selfie, pois, até então, encontrávamos apenas estudos de cunho gramatical que não correspondem à fluidez da língua. Sendo assim, realizamos uma discussão que aponta a falha dos discursos prescritivistas na tentativa de definir a palavra selfie, tanto em sua língua de origem, o inglês, bem como nas propostas definidoras para a utilização do gênero que antecede a palavra (o/a selfie) no espaço de enunciação do português do Brasil.

Em nosso gesto de leitura propomos outra possibilidade de significação para a palavra, que está relacionada a subjetividade. Enfatizamos que o surgimento desta palavra e sua possibilidade de significação em outros países está sustentada na memória da língua. Compreendemos também na formação da palavra selfie os efeitos da ideologia da globalização movimentando a língua.

Em uma palavra composta por seis letras, considerada um estrangeirismo no Brasil, temos os efeitos do contexto sócio - histórico, político e ideológico do século XXI, registrado. Algo que marca a opacidade da palavra selfie, sucumbindo a suposta neutralidade da linguagem. E na era de efervescência da tecnologia digital, da ideologia da globalização, mais criticamente teremos que olhar para as palavras.

\section{Referências}

ALTHUSSER, Louis. Ideologias e Aparelhos Ideológicos do Estado. Tradução de Joaquim José de Moura Ramos. Editorial Presença/Martins Fontes, 1970.

COSTA, G.C. da. A palavra do ano é uma imagem. Fragmentum, Santa Maria, Programa de Pós-graduação em Letras, UFMS, n. 48, 89-103, jul. - dez. 2016.

HAROCHE, Claudine. Fazer dizer, querer dizer. Tradução de Eni Pulcinelli Orlandi, com colaboração de Freda Indursky e Marise Manoel. São Paulo: Editora Hucitec, 1992. 
MAGALHÃES, B.; MARIANI, B. Processos de subjetivação e identificação: ideologia e inconsciente. Linguagem em (Dis)curso, Palhoça, SC, v. 10, n. 2, 391-408, maio/ago. 2010.

NUNES, José Horta. Dicionários: história, leitura e produção. Revista de Letras da Universidade Católica de Brasília - UCB. Volume 3 - Número 1/2 - ano III - dez/2010. p. 6-21.

ORLANDI, E.P. Discurso e texto: formulação e circulação dos sentidos. $4^{\text {a }}$ Edição. Campinas, SP: Pontes Editores, 2012.

PAYER, M.O. Memória da língua: imigração e nacionalidade. São Paulo: Escrita, 2006.

ROCHA LIMA, Carlos Henrique da. Gramática normativa da língua portuguesa. Prefácio de Serafim da Silva Neto. 40 ed. Rio de Janeiro: José Olympio, 2001.

Data de Recebimento: 19/05/2020

Data de Aprovação: 22/06/2020 


\section{Para citar essa obra:}

SOARES, Maraline Aparecida e NUNES, Silvia Regina. Da opacidade da palavra selfie no discurso digital in: RUA [online]. Volume 26, número 1 - Ahead of print - e-ISSN 2179-9911 jun./2020. Consultada no Portal Labeurb - Revista do Laboratório de Estudos Urbanos do Núcleo de Desenvolvimento da Criatividade.

http://www.labeurb.unicamp.br/rua/

Capa: Figura 03: Print da publicação da página DaLíngua Portuguesa

Laboratório de Estudos Urbanos - LABEURB

Núcleo de Desenvolvimento da Criatividade - NUDECRI

Universidade Estadual de Campinas - UNICAMP

http://www.labeurb.unicamp.br/

Endereço:

LABEURB - LABORATÓRIO DE ESTUDOS URBANOS

UNICAMP/COCEN / NUDECRI

CAIXA POSTAL 6166

Campinas/SP - Brasil

CEP 13083-892

Fone/ Fax: (19) 3521-7900

Contato: http://www.labeurb.unicamp.br/contato 